\title{
Investigation of the mechanical properties of composite polymer electrolytes based on $\mathrm{CsH}_{2} \mathrm{PO}_{4}$
}

\author{
Irina Bagryantseva ${ }^{1,2}$, Daria Dormidonova ${ }^{1}$, Valentina Ponomareva ${ }^{1-}$ \\ ${ }^{1}$ Institute of Solid State Chemistry and Mechanochemistry, 630128, Novosibirsk, Russia \\ ${ }^{2}$ Novosibirsk State University, 630090, Novosibirsk, Russia
}

\begin{abstract}
The mechanical properties of the $\mathrm{CsH}_{2} \mathrm{PO}_{4}$ and hybrid compounds with different polymers (SKF-26, UPTFE, Butvar B-98) was determined by the Vickers microhardness test for the first time. It was shown that increase in the volume fraction of the polymer results in the low HV values corresponding to the high robustness of the membranes to plastic deformation. Mechanical properties of hybrid compounds depend on polymer type and the best results were obtained for SKF-26. The improvement of mechanical properties makes the investigated composite polymer electrolytes promising for use as proton-conducting membranes in the medium-temperature range.
\end{abstract}

\section{Introduction}

The growing interest in high proton-conducting materials in the medium temperature range of $200-400^{\circ} \mathrm{C}$ is associated with their use in various electrochemical devices, including fuel cells (FCs). Electrolytes for FC application must have several required characteristics such as high proton conductivity, low electronic conductivity, low gas permeability, mechanical strength, and high chemical stability. The $\mathrm{CsH}_{2} \mathrm{PO}_{4}$ based membranes undoubtedly have great potential for application for a medium-temperature FCs due to the existence of the superionic cubic Pm-3m phase with high values of conductivity $\left(6 \cdot 10^{-2} \mathrm{~S} / \mathrm{cm}\right.$ at $\left.\mathrm{T}=240^{\circ} \mathrm{C}\right)$ [1-3]. Despite its attractive electrochemical characteristics, $\mathrm{CsH}_{2} \mathrm{PO}_{4}$ has poor mechanical stability due to the time-dependent plasticity of acid salts in superionic phases [1]. Electrolytes composed of pure $\mathrm{CsH}_{2} \mathrm{PO}_{4}$ can be deformed under compressive loading resulting in fuel leaks and voltage losses. Also, creep destroys electrode structure breaking the triple-phase boundary sites and lowering FC performance.

Researches on composite systems based on $\mathrm{CsH}_{2} \mathrm{PO}_{4}$ and polymer additives are being intensively developed. Such systems combine the strength, flexibility, and hydrophobicity of a polymer component with a high proton conductivity of an acid salt. Polymer additive makes it possible to obtain thin membranes thus reducing ohmic losses. In most cases, the crystal structure of the salt and its thermal properties were not affected by the polymer, while the proton conductivity decreased in proportion to the amount of the non-conducting

- Corresponding author: ponomareva@solid.nsc.ru 
polymer additive due to the «conductor-insulator» percolation effect [1-5]. According to the literature data, the mechanical strength of polymer composite electrolytes was investigated $[5,6]$. Mechanical tensile strength for the PVDF membrane demonstrated rather high values of $\sim 58 \mathrm{MPa}$. Composite electrolytes have a significantly lower tensile strength due to the addition of $\mathrm{CsH}_{2} \mathrm{PO}_{4}$ particles. So for a composite electrolyte with $70 \mathrm{wt}$. $\% \mathrm{CsH}_{2} \mathrm{PO}_{4}$, a tensile strength of $7 \mathrm{MPa}$ was obtained. With an increase in the salt content, a further decrease in the strength characteristics is observed [5] Similar results were obtained for composites based on $\mathrm{CsH}_{2} \mathrm{PO}_{4}$ with epoxy rubber and SPEEK [1,6]. Despite the decrease in strength characteristics, the mechanical stability of $« \mathrm{CsH}_{2} \mathrm{PO}_{4}$-polymer» composite electrolytes significantly exceeds the initial salt. As for the mechanical properties of pure acid salts of the $\mathrm{M}_{\mathrm{n}} \mathrm{H}_{\mathrm{m}}\left(\mathrm{AO}_{4}\right)_{\mathrm{p}}$ family (where $\mathrm{M}=\mathrm{Cs}, \mathrm{Rb}, \mathrm{NH}_{4}{ }^{+}, \mathrm{A}=\mathrm{P}, \mathrm{As}, \mathrm{S}$, Se, and $\mathrm{m}, \mathrm{n}, \mathrm{p}$ are integers) there is no detailed information. Mechanical properties of $\mathrm{CsHSO}_{4}$ and $\mathrm{KH}_{2} \mathrm{PO}_{4}$ have been investigated [1-3]. For tetragonal $\mathrm{KH}_{2} \mathrm{PO}_{4}$ single crystal, the value of the large-load Vickers hardness $\sim 1.4 \mathrm{GPa}$ was estimated as the load-independent and orientation insensitive [13]. Along with tensile strength measurements and 3-point flexural testing of the composite membranes, nanoindentation is a perspective method to evaluate the mechanical properties of materials. Vickers hardness test is used to observe the ability of a material to resist plastic deformation from a standard source with a diamond in the form of a square-based pyramid as an indenter.

This work is devoted to the study of the mechanical properties of polymer composite electrolytes based on $\mathrm{CsH}_{2} \mathrm{PO}_{4}$ by the Vickers method. As a polymer additives copolymer of vinylidenefluoride with hexafluoropropylene (SKF-26), ultradispersed polytetrafluoroethylene (UPTFE Forum ${ }^{\circledR}$ ) and polyvinyl butyral (Butvar ${ }^{\circledR}$ B98) were investigated. The studied polymers have a high decomposition temperature $\left(\sim 250^{\circ} \mathrm{C}\right)$ are chemically stable and are resistant to the action of many aggressive media. Previously the detailed studies of the synthesis method, transport characteristics, structural properties, and morphology of the polymer composite membranes have been carried out [7 - 9].

\section{Experimental section}

The microindentation test provides a simple way to evaluate the mechanical properties of composite polymer electrolytes. For mechanical properties investigation $\mathrm{CsH}_{2} \mathrm{PO}_{4}$ powder was uniaxially pressed in a cylindrical compression die for $10 \mathrm{~min}$ at a pressure of $300 \mathrm{MPa}$ at room temperature to yield disc specimens of $5 \mathrm{~mm}$ in diameter and $1 \mathrm{~mm}$ thick. Composites with various polymer content $\mathrm{x}(\mathrm{wt}, \%)$ were obtained by different methods. Composites of the $\mathrm{CsH}_{2} \mathrm{PO}_{4}$-UPTFE system were obtained by solid-state technique due to the insolubility of UPTFE in common solvents. The appropriate amount of components was mixed and hot-pressed at $\mathrm{T}=140^{\circ} \mathrm{C}$ to form a dense tablet. For cesium dihydrogen phosphate, there are no common solvents with SKF-26 and Butvar polymer. The hybrid membranes were obtained by mixing of $\mathrm{CsH}_{2} \mathrm{PO}_{4}$ salt particles with a polymer solution in a suitable solvent with a mortar and a pestle with a further drying and uniaxial pressing of formed powder at $300 \mathrm{MPa}$ into a dense tablet. The relative density of the obtained tablets « $\mathrm{CsH}_{2} \mathrm{PO}_{4}$-polymer» was $~ 91-95 \%$.

The Vickers hardness test was performed on Microhardness tester DuraScan 50 (EMCO-TEST, Austria). The indentation load was $0.5 \mathrm{kgf}(4.9 \mathrm{~N})$ with an applied time of 10 seconds. Measurements were reproduced at least ten times for each sample. The size of the indentation diagonals on the surface of the membrane after the removal of the load was measured with an optical microscope with a 10-times objective lens. The Vickers Hardness (HV) was obtained automatically by division of the load by the area of the sloping surface of the indentation. 


\section{Results}

The mechanical properties of the initial $\mathrm{CsH}_{2} \mathrm{PO}_{4}$ salt and hybrid polymer compounds were determined using the Vickers microhardness test. Figure 1 presents the changes of an impression on the surface of membranes of various compositions after the Vickers indentation.

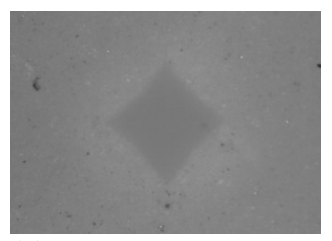

(a) $\mathrm{CsH}_{2} \mathrm{PO}_{4}$

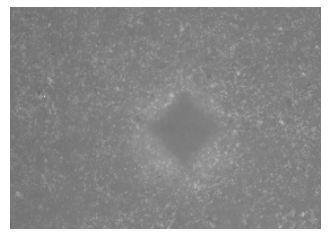

$\mathrm{x}=0.05(7.9$ vol. $\%)$

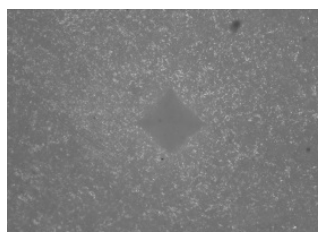

$\mathrm{x}=0.05(13.6$ vol. $\%)$

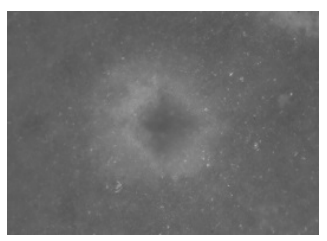

$\mathrm{x}=0.05(8.6$ vol. $\%)$

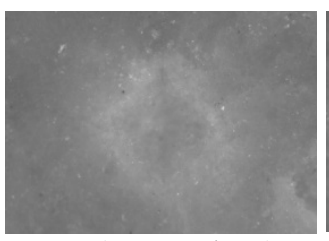

$\mathrm{x}=0.1(16.6$ vol. \% $) \quad \mathrm{x}=0.15(24$ vol. \%)

(b) (1-x) $\mathrm{CsH}_{2} \mathrm{PO}_{4}-\mathrm{xSKF}-26$

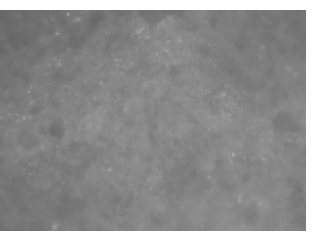

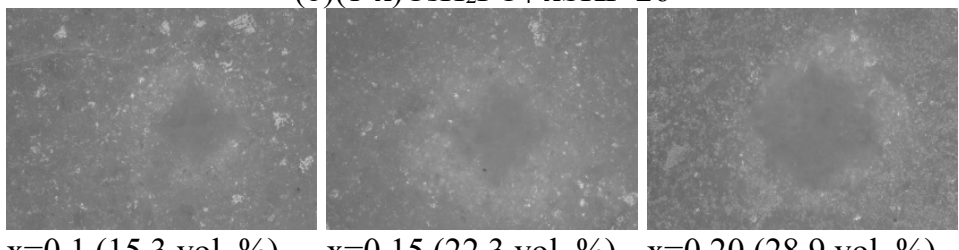

$\mathrm{x}=0.1(15.3$ vol. $\%) \quad \mathrm{x}=0.15(22.3$ vol. $\%) \quad \mathrm{x}=0.20(28.9$ vol. $\%)$

(c) $(1-\mathrm{x}) \mathrm{CsH}_{2} \mathrm{PO}_{4}-\mathrm{xUPTFE}$
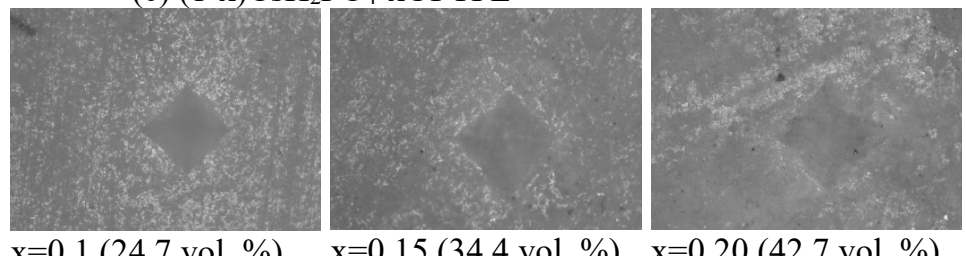

(d) $(1-\mathrm{x}) \mathrm{CsH}_{2} \mathrm{PO}_{4}$-xButvar

Fig. 1. The microscope images of the indenter impression on the membrane surface of the ${ }^{2} \mathrm{CsH}_{2} \mathrm{PO}_{4}-$ polymer» composites with different $\mathrm{x}$.

The microhardness for inorganic salt $\mathrm{CsH}_{2} \mathrm{PO}_{4}$ was $\mathrm{HV} \sim 34$, which corresponds to 333.4 $\mathrm{MPa}$ (Fig. 1a). For a hybrid compound with a SKF-26 polymer content $\mathrm{x}=0.05$ the microhardness is $\sim 19$ and reaches $\mathrm{HV} \sim 10$ for $\mathrm{x}=0.10(\sim 98.1 \mathrm{MPa})$. With further growth of polymer content to $\mathrm{x} \geq 0.15$ there were no visible impressions from the diamond pyramidal indenter (Fig. 1 (b)). For the higher x HV values can't be obtained because the indentation mark was quickly erased due to the small recovery time of the membranes with high fluoroelastomer content. For the $\mathrm{CsH}_{2} \mathrm{PO}_{4}$-UPTFE system a similar tendency was observed (Fig. 1 (c)). With $\mathrm{x}$ increase, the area of indenter impression increases corresponding to HV values decrease. It confirms that hybrid membranes can resist plastic deformation and their mechanical properties are higher. Besides the high content of fluorine in UPTFE, as well as in SKF-26, makes fluoropolymers promising as a matrix for $\mathrm{CsH}_{2} \mathrm{PO}_{4}$ due to stability in aggressive media, prolonged heating to high temperatures, and hydrophobicity.

Vickers microhardness of « $\mathrm{CsH}_{2} \mathrm{PO}_{4}$-polymer» systems depending on the volume fraction of polymer is presented in Fig. 2. Among all the systems studied, fluoroelastomer SKF-26 has the strongest effect on the mechanical properties of the membranes. For $\mathrm{x}=0.15$ that corresponds to $\sim 24$ vol. $\%$ there was no visible indenter impression. This result exceeds the values for the $\mathrm{CsH}_{2} \mathrm{PO}_{4}$-Butvar system even at higher volume fractions of the Butvar polymer additive, up to $45 \mathrm{vol} . \%$. 


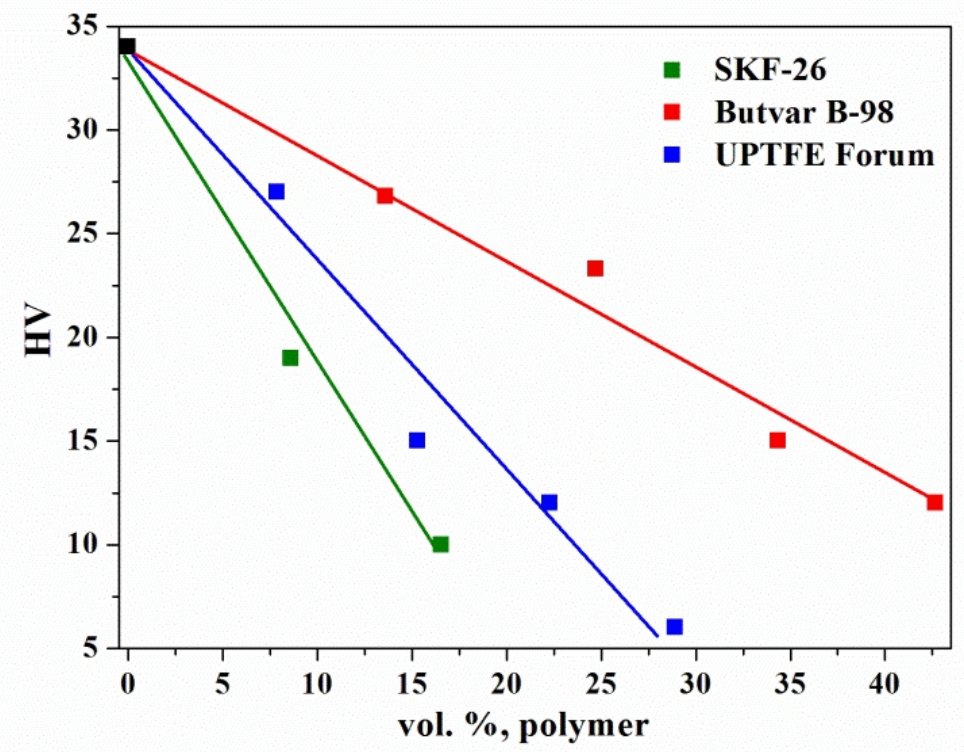

Fig. 2. Vickers microhardness of « $\mathrm{CsH}_{2} \mathrm{PO}_{4}$-polymer» systems.

\section{Conclusions}

The mechanical properties of the $\mathrm{CsH}_{2} \mathrm{PO}_{4}$ acid salt and hybrid polymer compounds with different polymers (SKF-26, UPTFE, Butvar B-98) were determined by the Vickers microhardness test for the first time. For hybrid compounds, it was shown that with an increase in the mass fraction of the polymer the ability to resist plastic deformation and mechanical strength increase, which makes the investigated composite polymer electrolytes promising for use as proton-conducting membranes in the medium-temperature range.

This work was supported by State Assignement to ISSCM SB RAS No 121032500065-5.

\section{References}

[1] S.M. Haile, C.R.I. Chisholm, K. Sasaki, D.A. Boysen, T. Uda, Faraday Discuss. 134, 17 (2007)

[2] T. Uda, S.M. Haile, Electrochem. Solid State Lett. 8, A245 (2005)

[3] A.I. Baranov, V.P. Khiznichenko, V.A. Sandler, L.A. Shuvalov, Ferroelectrics 81, 1147 (1988)

[4] L.F. Kirpichnikova, A.A. Urusovskaya, V.I. Mozgovoi, JETP Lett 62, 638 (1995)

[5] G. Qing, R. Kikuchi, A. Takagaki, T. Sugawara, ST Oyama, J. Electrochem. Soc. 161, 451 (2014)

[6] G. Qing, R. Kikuchi, A. Takagaki, T. Sugawara, ST Oyama, Electrochim Acta 169, 219 (2015)

[7] I.N. Bagryantseva, V.G. Ponomareva, N.P. Lazareva, SSI 329, 61 (2019)

[8] I.N. Bagryantseva, A.A. Gaydamaka, V.G. Ponomareva, Ionics 26, 1813 (2020)

[9] I.N. Bagryantseva, V.G. Ponomareva, V.R. Khusnutdinov, J. Mater. Sci. 2021 (to be published) 
[10] Q. Xie, Y. Li, J. Hu, X. Chen, H. Li, J. Membr. Sci. 489, 98 (2015)

[11] R.S. Ginder, G.M. Pharr, J Mater. Res. 34, 1130 (2019)

[12] R.S. Ginder, G.M. Pharr, Scr. Mater., 139, 119 (2017)

[13] T. Fang, J.C. Lambropoulos, J. Am. Ceram. Soc. 85, 174 (2002) 